\title{
Study on the Design of Outdoor Environment of Modern
}

\section{Residential Area}

\author{
Qiong Zhang ${ }^{1}$ \\ ${ }^{1}$ Hebei Academy of Fine Arts, Xinle, Hebei, 050700
}

KEYWORDS: Social Development; Human Settlements; Outdoor Environment

\begin{abstract}
With the rapid development of social economy and culture, increasing people's living standards, modern industrialization, urbanization, the increasing development, but also spawned a number of serious pollution of the natural environment, while solving the housing problem of the city, but never the other aspect brings comfort problems of city life. In order to create a better life for themselves, solve the problem of coordinated development of urban and rural areas, building space and natural space between many of our sages through the test of practice, we made a lot of planning and thought, theory and construction mode, for nearly a hundred years of exploration and research, to find workarounds for human living environment.
\end{abstract}

\section{Introduction}

For the study of modern residential outdoor environmental design, in fact, as early as it was long, long time ago has been explored, it is specifically targeted at the human living environment for requirements and experience, through a lot of time and research, made a lot of adaptation and social development progressive doctrine and ideology. After these doctrines and ideas, after a hundred years, we are now on the study of modern residential outdoor environmental design still has a role of guidance and inspiration. In these theories and ideas, the more famous are so few: with city, garden city, "organic decentralization" theory green cities.

As early as 100 years ago, our ancestors had to residential outdoor environmental design had extensive and profound research, and provide a good springboard for us to boost the role of today's study.

\section{The Concept of Outdoor Design}

For the study of modern residential outdoor environmental design, we need to understand the modern residential area for outdoor environment needs further research and discussion on this issue by supply and demand.

The concept of residential areas from 1929 American Institute of Architects C. Perry's "neighborhood unit" planning thought, he inherited this idea Howard's garden city concept "housing units "thought. In the era of civilization turn of the century as a structural arrangement orderly urban social forms and shapes. He believes that, in 
large cities, the number of vehicles due to the rapid growth of traffic on the living environment a great deal of interference, so his starting point the theory is that the number of effective internal control vehicle traffic residential areas, in order to protect the residents safe and quiet environment. Meanwhile, the active life of community residents to promote exchanges, closer to the neighborhood, the unit should also be provided with adequate living facilities. Thus, the neighborhood as a geographical unit, with the respect of basic infrastructure following four parts: primary school, a small garden and playground; shops; to ensure that residents within walking distance to reach the safety of public facilities; combination of building and street by the four stars six physical form part of a neighborhood's property:

Primary needs to have a reasonable size, as a basis for controlling the population size of a neighborhood. For example, do not let the students go to school across the street, within walking distance of the unit should not exceed half a mile, the population density of the actual land size of neighborhood units played a decisive role in the general population in 3000-5000 to control the people.

We set up a neighborhood surrounded by urban roads, urban roads are not able to pass through the interior of a neighborhood, but there may be enough leg width.

Four weeks set aside a certain neighborhood units required for each buildings open space, such as a small park, small garden.

In the center of a neighborhood store or public land set aside land for limited range of services to schools and social agencies, welfare agencies.

In the neighborhood around the unit must be set up multiple purchase, with easy living, lots of the best roads in the surrounding neighborhood or can easily place.

Neighborhood units have to set up a private street system, to be able to load the main road in proportion. The entire street network design should not only run but also easy to block cross-border traffic.

For such ideas to the community as a whole and to regulate the construction of C. Perry proposed in the late 1940s by US attention after getting a great deal of application and development in the world, many countries of the post-war reconstruction . Of course, this principle of neighborhood planning unit has also been a number of professionals and sociologists criticism and criticism, but we can not deny that the long-term impact on the future generations.

Alexander community planning model is composed of prominent American architectural theorist Christopher Alexander - put forward, the great architectural theorist established 253 model in his book "Pattern Language" on. Alexander's pattern language can make the place have a deeper quality, is based on experience relating to humanitarian dream, also established a pattern for our swords in their own homes.

Alexander's pattern language is a spatial aspect of the language of communication in the form to fill the gap between the community and the residents of the designer and advocate a participatory process in the form to contact gap space and social factors. He asked users to participate in the construction process of the entire community. 
Alexander's pattern language contains a lot of community building models, but these models can not be in a day or can be designed to do it, but after a slow gradual development, from design through some way:

Everyone always acted help to create or produce these larger global mode, and is determined not to move slowly and, after a number of years to form integrated model containing these communities.

New Urbanism order to re-stimulate the vitality of urban communities in the United States the rise of the "New Urbanism" design philosophy and social thoughts of the 1980s, it is ignored by the United States for nearly half a century revival of traditional communities, also known as the "new traditionalism." It is in the traditional concept of urban planning and design thought, combined with the needs and conditions of modern life, many from the perspective of innovation, able to build a modern accepted and loved, and yet traditional atmosphere of the neighborhood community.

The United States after World War II, the population expands the gradual deterioration of urban living environment, serious environmental pollution. Because it was cheap land on the outskirts of the sound environment, so a lot of people in pursuit of a better, more comfortable living environment, they have moved to the suburbs from the city. During this period, "functional area" theory led to a lot of stand-alone residential, purely to provide people appear rest space community. But this community in the development process used by many of the shortcomings exposed, such as a lot of land on the outskirts of wanton use by people occupied; heavier traffic load in the city; for the lack of low-income dwellings; a sense of stability and social loss of identity.

Therefore, in order to resolve this situation, "New Urbanism" appears and the rapid development of popular. And have the following characteristics: First, respect for nature, the establishment of a complete urban ecosystem; the second is respect for the individual and society, the establishment of a human face in the community; the third is to maintain diversity, maintain the stability of urban ecosystem;

In the rapid economic development of contemporary society, the interests of all the time is not in the first place, as a residential area developers, they carefully planned residential space modeling and use, there is no consideration to spiritual issues, has been, environment and people's spiritual environment of residential areas is two irreconcilable contradictions, but now the economic supremacy of the society, our planners when conducting research plan for humanity's lack of care and consideration, without taking into account the material-oriented architecture for It affects people's spiritual level, which in turn leads to many problems. To avoid this problem, planners at the beginning should depart from management, people-oriented, rational use of land space but also concerned about the feelings of the people, people-oriented, interests second, designed for all ages, each groups can adapt to the residential area, so as to improve the environmental quality of residential areas.

Modern residential area of the outdoor environment is urban, not part of a separate viewing area, we have a region residential outdoor environmental design, it should be considered in advance to go to study and understand the cultural connotation of the 
region, it is unique, personal insights and character design. Design, to fully reflect local ethnic customs, behind the far-reaching historical and cultural connotation can not reimbursing copy, old-fashioned reference, resulting in subsequent stereotyped phenomenon. So the next designer in the design and should pay attention to the design layout, style, characteristics, content and style.

Many residential areas in pursuit of luxury, atmospheric type of dress, a wide range of rigid floor, flooding the square, close to the people and can not reflect the soft feel. In addition, many of the facilities in the closed state, in addition to outside the space occupied, resulting in a waste of resources. Excessive pursuit of luxury, the atmosphere, exotic and decorative is to the neglect of its usefulness. Basically it brings residents enjoy much comfort. To do so, on the one hand, such a large investment, but will not lead to corresponding benefits. On the other hand, they can not adapt to the cell's environment.

Green residence in the steel and concrete of the city is like an oasis in the desert, is the speed of a big modern city can only become a leisure entertainment place, so, for the greening of attention is the importance for residents of the humanities, for human attention. Green is people relax soul sustenance and support, enjoy the beautiful and comfortable environment in pursuit of fashion and art at the same time.

Designers excessive reliance decorative plants, the use of a large amount of floral decorations, but this will cost a lot of manpower and resources, pruning, maintenance. But in the summer, a lot of people who want to enjoy a moment of rest can not do, a lot of modifications flowers occupy a lot of space, it will cause people to want to rest at the time of settled space can not be found.

Blindly copying others green way, some of the exotic plants a lot of locally grown, in this way the price is great, can not help but cause biological invasion, in addition to mutations in weather and climate, it will lead to a series of problems occur .

Laying a lot of blind grass, it does have its own unique, but compared to trees, grass maintenance of its three to four times, and it is not the role of trees and a quarter of the environment, and if not timely conservation, grass can easily be eroded or other bare grass. We will pay and harvest is very uneven. Therefore, when using the lawn, it must be cautious and reasonable, after a careful calculation of the fine.

\section{Conclusion}

Environment residential area, is the condition for the survival of human factors, in addition to our above mentioned residential area outside the outdoor environment for physical and mental health and mental health of residents, some from the other side, if the designer for the modern the design process residential outdoor environment is too simple and rough, no sense of responsibility, today more and more people in the pursuit of quality of life of the social background, their design will be set aside public opinion. Therefore, in order to prevent such a similar situation, our designers design for modern residential area outdoor environment design must have a high sense of responsibility and commitment degrees.

In the future social development, follow the man in harmony with nature slogan, follow people-oriented, caring for the environment, the trend of environmental 
protection, follow to maintain their high level of political consciousness and moral principle, take seriously their work on their own work carefully and love is our designers should be noted that the big problem.

Based on people for the environment increasing attention, we must carefully design study of modern residential area outdoor environments, there are far-sighted and confidence, perseverance to adhere to develop and open look on the discovery and emergence each of the questions, detailed solutions for the future social and human development to lay the foundation, as well as a good example in the past.

Special populations are in the face of the elderly, the disabled and children, when, to their needs and the need to take into account their own designs to go.

\section{REFERENCE:}

[1] Huang Ping. Accessible Design [J]. Building, 2004 (4): 39-241.

[2] Wen Yicheng, $\mathrm{Xu}$ Yihong. The full range of outdoor environment accessible design [J]. Sichuan Building, 2000 (5): 77-279.

[3] Zhang Pin, Peng Jun. Ergonomics and living environment accessible design [J]. decoration, 2003 (3): 61-64.

[4] Chen Yingzhou, Song Jianxia, Deng Xiaoli. cell characteristics - Development of accessibility design planning [J]. Ningxia Engineering Technology, 2002 (4): $16-21$.

[5] Chen Ting. Garden accessible design [J]. Chinese gardens, 2002 (3): 79-81. 